\title{
How Sustainable Is Our Wastewater Treatment?
}

\author{
Stig Morling \\ Sweco Environment, Stockholm, Sweden \\ Email: stig.morling@sweco.se
}

Received 12 July 2014; revised 5 August 2014; accepted 28 August 2014

Copyright (C) 2014 by author and Scientific Research Publishing Inc.

This work is licensed under the Creative Commons Attribution International License (CC BY). http://creativecommons.org/licenses/by/4.0/

(c) (i) Open Access

\section{Abstract}

The sanitation and environmental problems related to human activities can be traced at least around 2500 years back, with written evidences both in the Old Testimony and the Greek culture. Thus in this perspective the matter is by convention an acknowledged problem since long. On the other hand our modern treatment systems of wastewater have far more recent roots. As an example, this year the very widespread biological treatment based on activated sludge celebrates it 100 year anniversary. In this perspective we may see a fundamental need to discuss and scrutinize the current systems in a "sustainable" perspective. A challenge for the technical society is to provide some "quantified" criteria on the concept sustainability. The wastewater treatment systems as we know them and develop them may be addressed by applying four major "sustainability" criteria: 1) The sustainability from major sanitation viewpoints; 2) The sustainability from environmental viewpoints; 3) The financial sustainability for the technical systems; (4) The sustainability with respect to adopting the systems into a more or less consistently changing society.

\section{Keywords}

Nitrogen, Nitrification, Phosphorus, Sanitation, Sustainability, Wetland

\section{Historic Background}

Our (western) knowledge of water environment and sanitation issues may be traced back to the arid cultures in the eastern Mediterranean rim, especially early statements from the Old Testimony and the classic Greek culture. In Deuturonium we find regulations for a dry handling of our feces, while the prophet Ezekiel is directly concerned with the pollution of the water sources (Ezekiel 34:18), quote:

"Seemeth it a small thing unto you to have eaten up the good pasture, but ye must tread down with your feet the residue of your pastures? and to have drunk of the deep waters, but ye must foul the residue with your feet?" [1]. Similar concern of the water quality is found in early Greece, where the poet Hesiodos, more than 600 years 
BC, stated: "Do not pollute a river running to the sea or the fresh water well byurine, nor empty your stomach there, it is as condemnable."

Contemporary and later on, as Rome became one of the early big cities in the world the water supply and water sanitation issue became important. Already before the birth of Christ the Cloaca Maxima was built, the oldest part as early as in the seventh century B. C. Parts are still in operation for storm water, see Figure 1.

Probably Rome also faced the first ever waste fee, as the emperor Vespasianus introduced the fee for official toilets in the city—around year 70 AD "Money does not smell". Much later, in late medieval time (1427 AD) in England an Act on Sewers was implemented [2]. This again reflects the relation between on one side growing towns and cities and on the other hand the deemed rational way to use water to transport the impurities. The modern wastewater handling may have had the starting point in Britain in mid- $19^{\text {th }}$ century, as the sanitation aspect was brought about in a more scientific perspective. Medical doctors in both Nottingham and London observed the relation between polluted water and diseases. The way to a modern wastewater treatment system went through use of land treatment and use of dilution of polluted waters using the tide rhythm. The break-through of what we today acknowledge as established treatment methods could be traced back to the first years of the last century. The nowadays widespread activated sludge technology was first presented by Arden and Lockett in 1915 [3].

The conviction that the major necessity of wastewater treatment was to establish a good and safe sanitation environment was still in focus. Thus the scientific discipline related to water and wastewater is still labeled "Sanitation". Since these early decades of the last century the focus has shifted to a concern on the water environment.

\section{Fundamental Aspects on a Sustainable Wastewater Treatment}

When viewing the wastewater treatment from a sustainable perspective there are a number of "scientific philosophy" points to address:

- The needed knowledge is normally insufficient to fully understand and cover the complex problems in the industrialised world. An example that may illustrate this matter is what we sometimes call the "chemical society" eagerly develops a large number of new products for the assumed benefit of society and consumers. On the other hand may the long term negative health or environmental side-effects be revealed only after generations. Nevertheless we must work and use our knowledge at our best ability for the time being.

- The contribution from natural scientists and the engineering society to the understanding of "sustainability" would be to try to quantify the problems. Or in other words-to enlighten the importance to find ways to measure adequately the relevant pollution variables, and thus quantify points related to sustainability. In our perspective limited to wastewater treatment this means to focus on health, environmental, technical and economical sustainability. Only to a lesser extent the "soft parameters" related to social sustainability would be addressed.

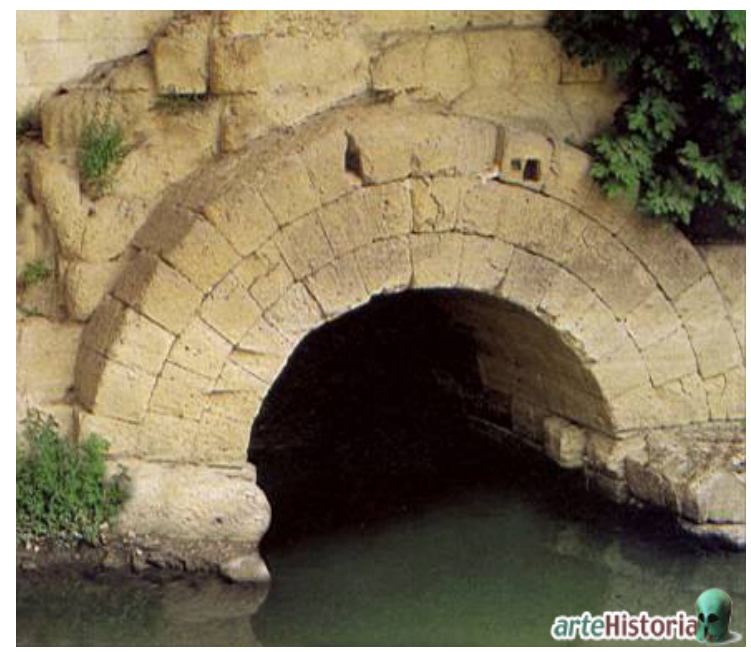

Figure 1. Cloaca Maxima in Rome, still in operation. 
- There would be a comprehension that the sustainability is time related. No system will be sustainable "for ever". We must even acknowledge that sometimes our conclusions have been based on insufficient, premature or even false conditions.

- The demand on cost efficiency, measured by various tools, such as cost benefit analysis, environmental impact assessment and so forth will always be an important postulate when defining a sustainable project.

- The demand for a good and efficient environmental protection is often basic or even fundamental when it comes to the planning and operation of a wastewater treatment plant - thus this demand is not understood as a part of the sustain-ability.

- The fundamental demand on a wastewater treatment plant is to safeguard a stipulated discharge quality of the wastewater. Often this fact will shadow the (implicit) demand: To provide a sustainable discharge of purified water, thus contributing to an improved environmental situation.

Many of the criteria are by convention used as key decisions on investments, but some may be seen as "unique" for wastewater treatment:

- A demand on establishing and maintaining a safe sanitation situation;

- Environmental protection of the receiving water bodies;

- To avoid that unwanted water is distributed to the treatment facility (normally storm water);

- Protection of the plant from unwanted or toxic pollution;

- Demand on an economically feasible solution;

- The plant would be able to operate at least during a stipulated time horizon;

- The configuration of the plant would be as flexible as possible in order to meet variations of the load during the year as well as future needed modifications (if possible to foresee).

However, these criteria may not be sufficient tools for a comprehensive decision on a forthcoming treatment facility. From environmental, technical as well as social aspects some additional criteria may be raised:

- The social and political acceptance is imperative seeing the investment as an essential task to fulfil the given criteria;

- The use of consumables, such as electric power and chemicals would be kept as low as possible;

- To use "natural" processes, to include a re-use/re-cycle material and nutrients as far as possible;

- To occupy a limited area for the plant, as competing activities and defined "safety distances" from the plant to housing areas will put restrictions on the land use;

- Last but not least any plant performance is dependent on the accurate and skilled operation and maintenance; otherwise the "sustainability" will not be in place.

All these criteria give a rather complex scheme for a proper selection of a treatment system. To some extent and in some cases the criteria may even be found as more or less "contradictive". This in turn may be one of the causes why the wastewater treatment concept as such sometimes is questioned.

\section{The Sustainability from Major Sanitation Viewpoints}

For the last four to five decades strong concentration on the environmental concern for the water environment has sometimes overshadowed the need for a sanitation perspective related to sustainability.

This perspective has however lately become once again more important. This is to a large extent related to incidents in the water supply sector. The fundamental demand on the water companies-either public or privateis to deliver safe and high quality potable water. In the last few years an elaborated philosophy on safe water production and supply has brought about refined perspectives.

Today we design and build water treatment plants with so called barriers. These barriers are aimed to safeguard the high sanitation standards on the potable water. In this respect it is interesting to observe the shift from chlorination techniques into advanced filtration followed by other treatment stages, such as UV-radiation, ozone treatment and similar techniques.

This development of "barrier-thinking" is now becoming a part of the new forthcoming wastewater treatment technology. Advanced filtration models such as the "Bio-membrane systems" may pave the way to an improved sanitation standard of the treated wastewater.

Another aspect on sanitation is the working environment at the wastewater treatment plant itself. As the modern plants are becoming more complex, and more process stages are built in, the health and safety risks for the onsite workers have become even more important. Three examples may illustrate the matter: 
- The pre-treatment facilities are to handle the most unpleasant and in some perspective "risky" matters at the treatment plant. Considerably much improved safety arrangements for the working staff is now built in;

- The sludge treatment and handling represents the second part at a treatment plant. There may be evident risks for an unwanted and uncontrolled exposure of non hygienezed sludge for the working staff;

- The potential re-use of the sludge as a fertilizer has been a subject for considerable attention for health and long-term risks. The focus has primarily been on the heavy metal content in the sludge, but also on more complex matters, such as chlorinated organic compounds.

This "re-entry" of the sanitation aspect on the wastewater treatment handling would be seen as a necessary improvement of the sustainability in this field.

\section{The Sustainability from Environmental Viewpoints}

As pointed out above our knowledge may always be more or less insufficient at any given time. To some extent this matter may be reflected by the often given formal environmental permission time that has been set at 10 years, or even less. On the other hand it may be concluded that the actually exercised changes in formal revisions on effluent standards has been about 15 years. Some examples may be given from the Swedish theatre:

- During the 1950-is the effluent standards focused on BOD removal;

- In the late 1960-is it was apparent that phosphorus played a major role as pollutant, especially due to the "secondary oxygen consumption”. From 1969 a large number of plants were built mainly based on advanced chemical phosphorus removal throughout the country.

In mid-1980s an "explosion" of algae growth in the water bodies on the Swedish west coast made the nitrogen removal a major issue, especially related to the discharges from the coastal plants in mid and southern Sweden. This in turn changed the effluent standards to include also limitations on nitrogen. At the same time more stringent standards were implemented on both total $\mathrm{P}$ and $\mathrm{BOD}_{7}$. These levels have been further refined and are to a large extent in compliance with the EU directive, Council directive EEC 91/271 [4], apart from a geographical view - the discharges from plants in northern Sweden have no limitations on nitrogen removal.

As an example a comparison between the currently exercised EU directive and adopted effluent standards for a major Swedish plant is given in Table 1.

Now you may put a critical question to this development: Is the aspect of a safe sanitation neglected in favour of the more or less well defined water environment conditions? A perspective of the water environment protection may not be sufficient in a sustainable perspective.

\section{The Financial Sustainability for the Technical Systems}

The issue of financial sustainability may to a large extent be seen as a reflection of the political and social acceptance of costs for a safe sanitation and good water environment. Historically handling of refuse and wastewater has been seen as inferior activities with little prestige linked to the needed work. The attitude is reflected by ignorance from both citizens and politicians regarding the actual cost for water.

However, a comprehensive cost and benefit analysis, along with attempts to evaluate the life cycle costs for different treatment options represent necessary work tools when selecting a treatment system.

Table 1. Effluent standards according to EU directive EEC 91/271 and adopted and anticipated standards for the Stockholm Water plants (values in $\mathrm{mg} / \mathrm{l}$ ) the Stockholm Water plants (values in $\mathrm{mg} / \mathrm{l}$ ).

\begin{tabular}{cccc}
\hline Pollution variable & EEC 91/271 & $\begin{array}{c}\text { Stockholm water standards, } \\
\text { currently ruling }\end{array}$ & $\begin{array}{c}\text { Stockholm water revised } \\
\text { (indicative) standards }\end{array}$ \\
\hline BOD & $<25$ & $<8$ & $<6$ \\
COD & $<125$ & $(<70)$ & $(<70)$ \\
SS & $<35$ & n.a. & n.a. \\
Total N & $<10$ & $<10$ & $<6$ \\
Total P & $<1$ & $<0.3$ & $<0.2$ \\
\hline
\end{tabular}




\section{The Sustainability of Wastewater Treatment in Relation to an Ever Changing World}

The perspective of the continuously changing physical and social environment may be seen as a challenge also for the wastewater treatment handling. As pointed out at the beginning of this paper, our knowledge may be found insufficient in some respects. This in turn will call for re-thinking, further research and development efforts, and also to find new treatment combinations to meet the challenges. In this chapter two different examples will be highlighted.

The first example is related to biological treatment systems. The following text is quoted from a scientific paper published recently [5]:

"Current biological wastewater treatment strategy may, very simplified, be defined by two quite different main strategies: The first one based on more advanced and compact technologies, such as different types of enhanced microbiological models, either attached growth or suspended sludge systems i.e. activated sludge of different modes. The second one, on the other hand seen as simple 'green solutions' based on extensive models such as multi-stage oxidation ponds, infiltration systems, wetlands and root zone technologies. Sometimes these models are presented as 'competitors' and arguments are raised for one of the basic model to be superior."

This paper relates to an alternative approach, where the combination of a "classic" wastewater treatment facility integrates a polishing step based on a multi-stage constructed wetland. The operation has successfully been in place for 10 years. Figure 2 presents the treatment train for the plant.

The paper summarizes the findings from ten year's operation as follows, though some specific conclusions are excluded:

- The ability to run the wetland throughout the year has been established since the introduction of the SBR-system (Sequencing Batch Reactor-system). The introduction of this stage has contributed to the improved results;

- From many aspects the wetland performed well after upgrading of the plant, providing discharge levels of BOD7 and the total P of very high quality. The inlet BOD-concentration to the wetland has decreased from about $30 \mathrm{mg} / \mathrm{l}$ to slightly above $10 \mathrm{mg} / \mathrm{l}$, and the discharge of BOD is almost consistently less than $3 \mathrm{mg} / \mathrm{l}$;

- The wetland facility has performed a very good nitrification and denitrification. Typical discharge level of total nitrogen is now below $7 \mathrm{mg} \mathrm{N} / \mathrm{l}$;

- The total P-concentration has been decreased by about 50\% from about 0.12 to $0.06 \mathrm{mg} / \mathrm{l}$ (annual average);

- The previously observed problem with odours from the inlet part of the wetland has disappeared;

- The need for chemical precipitant (alum salt) has been reduced by 50\% as compared with previous operations;

As a summary the Nynäshamn plant may serve as an interesting example complying with the above criteria on what may be seen as a "sustainable" wastewater treatment facility.

The second example may serve as a very challenging perspective on sludge management.

The current paradigm when sludge stabilization and re-use are discussed is to use the sludge for biogas production.

A radical challenge to this model may be the "Hydro Thermal Carbonization" (HTC process).This treatment model is by no means a new one; it is based on nature's “own” way of producing crude oil during controlled conditions-presence of organic carbon, high temperature and pressure during acidic conditions. Practical research and process development specifically on municipal sludge demonstrates the potential to recover $80 \%$ to $95 \%$ of the organic carbon in a concentrated stream after treatment according to the tests a total treatment time would be in the vicinity of less than 24 hours, to be compared with the bio-gas model that needs 12 to 15 days for a safe and stable production of biogas.

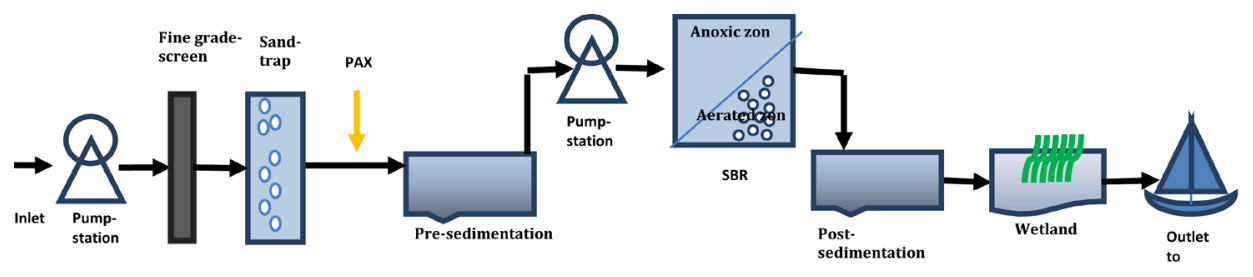

Figure 2. Simplified flow sheet of the Nynäshamn WWTP. 
A simple comparison of the models point out that the HTC-would potentially deliver around 2.5 to 3 times more carbon available for energy production in comparison with the now dominant bio-gas technology. A number of studies and technology developments are available. In this context references are made to two studies ([6] and [7]. Recent research in small scale has demonstrated the possibility to refine the concentrated carbon product into activated carbon. This in turn points out that the carbon as concentrated by the HTC process may be seen as a raw material for various needs.

These two examples may serve as-perhaps somewhat provocative-situations where once accepted knowledge is questioned, and the need for additional pathways is shown in striving for even better "sustainable wastewater treatment" is illustrated.

\section{Summary and Conclusions}

This paper deals with the very central issue of sustainability in wastewater treatment. The fundamental point is that only an open mind to needed changes and new insights may at the end of the day be the true "sustainable" method to develop the wastewater treatment to needed improvements and an extended sustainability.

\section{Acknowledgements}

This paper has been scrutinized by my colleague Åsa Westlund, who also is the main writer of the paper on Nynäshamn WWTP, see [5]. Mr. Guy Taylor has done the needed linguistic scrutinization of the text. Thank you both!

\section{References}

[1] King James Bible “Authorized Version”. www.kingjamesbibleonline.org

[2] Sidwick, J.M. and Murray, J.E. (1976) A Brief History of Sewage Treatment. Effluent and Water Treatment Journal, 65-71.

[3] Arden, E. and Lockett, W.T. (1915) The Oxidation of Sewage without the Aid of Filters. Journal of the Society of Chemical Industry, 827-943.

[4] European Union (1991) Council Directive 91/271/EEC Concerning Urban Waste Water Treatment.

[5] Morling, S., Franquiz, A., Måhlgren, J. and Westlund, Å (2014) Long Term Experiences of SBR-System and Wetland Treatment from a Municipal WWTP in Sweden, Operated with Low Temperature Wastewater. Water Practise and Technology, 9, 235-242. http://dx.doi.org/10.2166/wpt.2014.027

[6] Hu, B., Wang, K., Wu, L.H., Yu, S.H., Antonietti, M. and Titirici, M.M. (2010) Engineering Carbon Materials from the Hydrothermal Carbonization Process of Biomass. Advanced Materials, 22, 813-828. http://dx.doi.org/10.1002/adma.200902812

[7] Lilliestråle, A. (2007) Hydrothermal Carbonization of Biowaste-A Step towards Efficient Carbon Sequestration and Sustainable Energy Production. Master Thesis, Molecular Biotechnology Programme, Uppsala University, Uppsala, Sweden. 
Scientific Research Publishing (SCIRP) is one of the largest Open Access journal publishers. It is currently publishing more than 200 open access, online, peer-reviewed journals covering a wide range of academic disciplines. SCIRP serves the worldwide academic communities and contributes to the progress and application of science with its publication.

Other selected journals from SCIRP are listed as below. Submit your manuscript to us via either submit@scirp.org or Online Submission Portal.
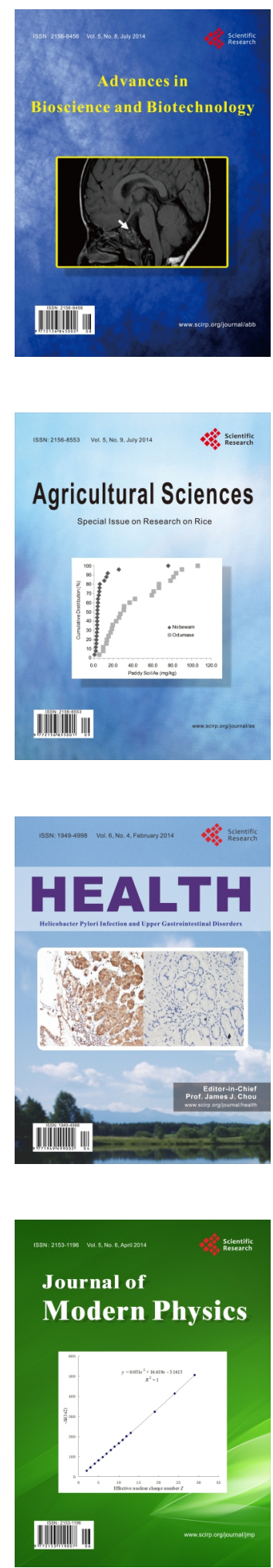
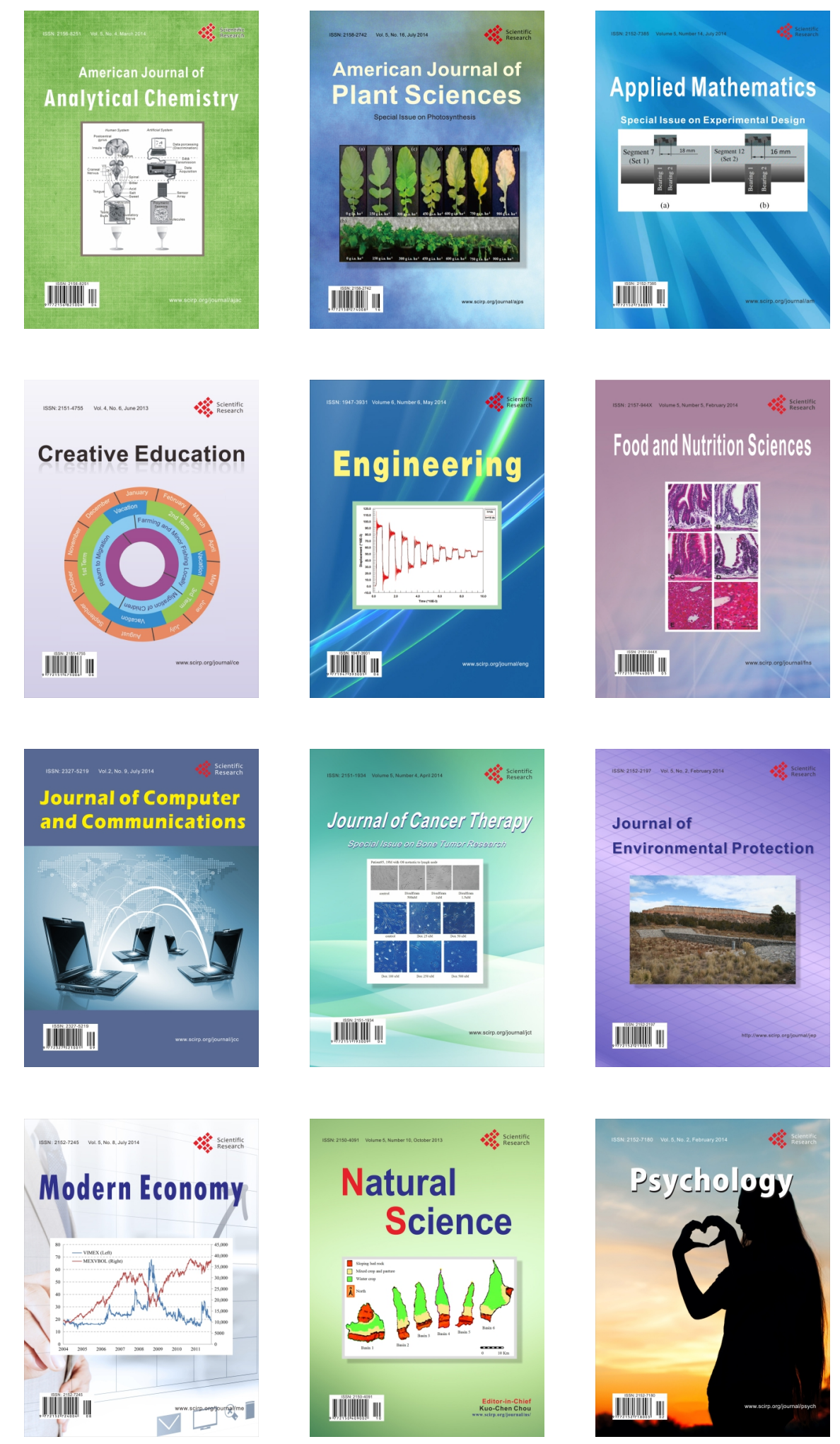